\title{
Infographic: the Pneumatic Retinopexy versus Vitrectomy for the Management of Primary Rhegmatogenous Retinal Detachment Outcomes Randomized Trial (PIVOT)
}

\author{
Declan C. Murphy $\mathbb{D}^{1} \cdot$ Nikolaos Tzoumas $^{1} \cdot$ Alex Mehta $\mathbb{D}^{1} \cdot$ Islam Mostafa ${ }^{1} \cdot$ Salman N. Sadiq ${ }^{1} \cdot$ Anna Song $\mathbb{D}^{1} \cdot$

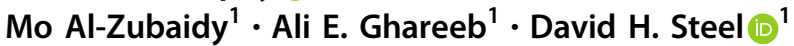

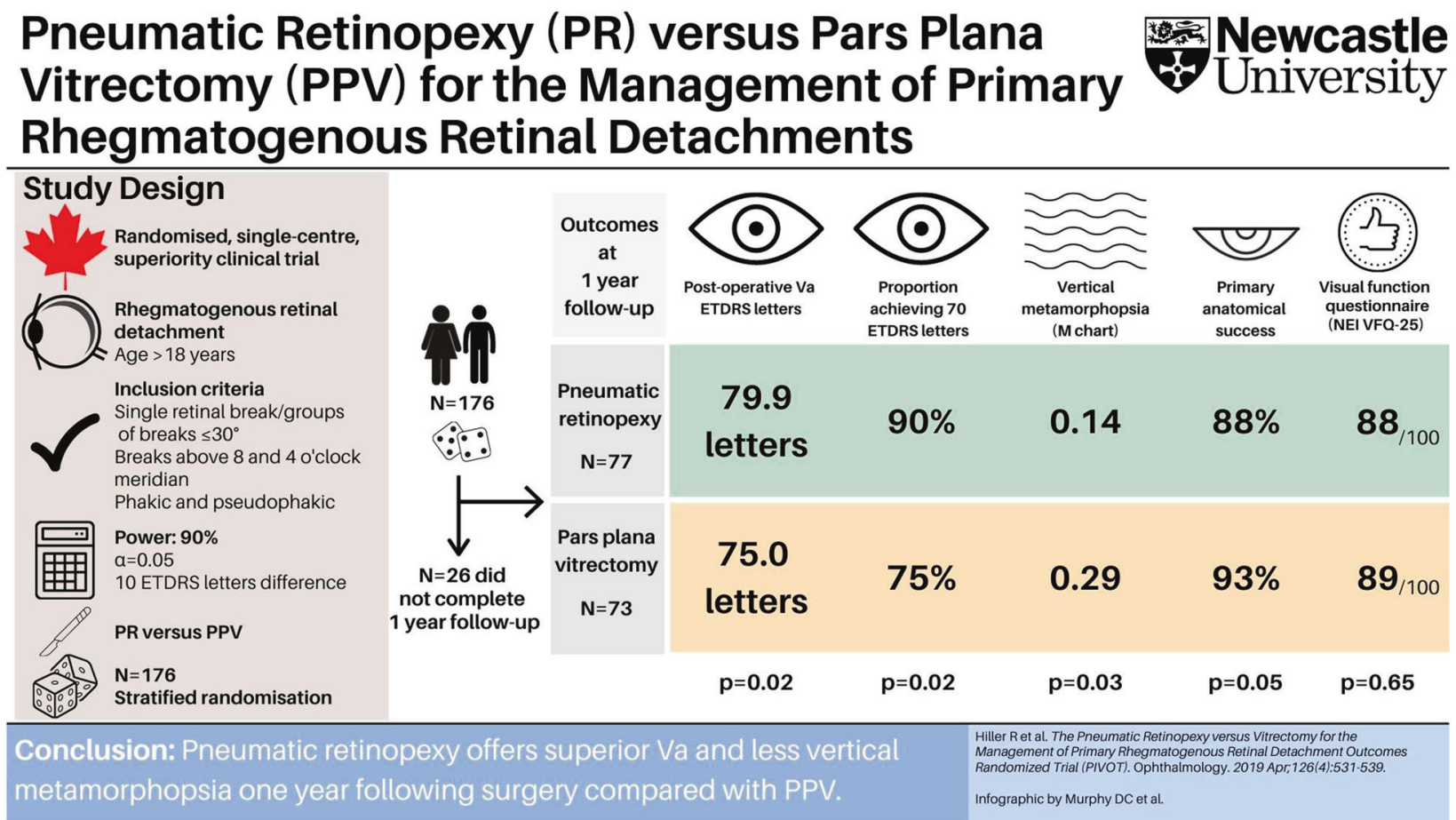

Fig. 1 The Pneumatic Retinopexy versus Vitrectomy for the Management of Primary Rhegmatogenous Retinal Detachment Outcomes Randomized Trial (PIVOT) showed that at 1 year following surgery, pneumatic retinopexy achieved superior outcomes in terms of visual acuity and vertical metamorphopsia. There was no significant difference in patient-reported subjective visual function between the two surgical interventions. Abbreviations: ETDRS Early Treatment Diabetic Retinopathy Study, NEI VFQ-25 questionnaire National Eye Institute Visual Function Questionnaire, PPV pars plana vitrectomy, PR pneumatic retinopexy, Va visual acuity.

Reference: Hillier RJ, Felfeli T, Berger AR, Wong DT, Altomare F, Dai D, et al. The Pneumatic Retinopexy versus Vitrectomy for the Management of Primary Rhegmatogenous Retinal Detachment Outcomes Randomized Trial (PIVOT). Ophthalmology. 2019;126:531-9. https://doi.org/ 10.1016/j.ophtha.2018.11.014. 
Open Access This article is licensed under a Creative Commons Attribution 4.0 International License, which permits use, sharing, adaptation, distribution and reproduction in any medium or format, as long as you give appropriate credit to the original author(s) and the source, provide a link to the Creative Commons license, and indicate if changes were made. The images or other third party material in this article are included in the article's Creative Commons license, unless indicated otherwise in a credit line to the material. If material is not included in the article's Creative Commons license and your intended use is not permitted by statutory regulation or exceeds the permitted use, you will need to obtain permission directly from the copyright holder. To view a copy of this license, visit http://creativecommons. org/licenses/by/4.0/.

\section{Compliance with ethical standards}

Conflict of interest The authors declare no competing interests.

Publisher's note Springer Nature remains neutral with regard to jurisdictional claims in published maps and institutional affiliations. 